\title{
SAÚDE NO PENSAMENTO DE D. W. WINNICOTT: EM BUSCA DOS IGARAPÉS
}

\author{
HEALTH IN THE THOUGHT OF D.W. WINNICOTT: IN SEARCH OF IGARAPÉS
}

Ana Letícia Martins de Souza*

\begin{abstract}
RESUMO
A comunicação apresentada no Simpósio Filosofia e saúde do Departamento de Filosofia da PUC Minas, em maio de 2021, teve como objeto o pensamento de Donald Woods Winnicott e seu interesse para a Filosofia. Após breve apresentação do autor, expôs-se seu pensamento sobre o desenvolvimento humano a partir dos pilares da unidade psicossomática e da teoria do amadurecimento pessoal. Visou-se evidenciar sua noção de saúde e respectivas consequências para o campo científico, notadamente as ciências médicas, mediante abordagem que vai além da esfera do organismo e que pretende superar a dicotomia mente-corpo. Com ênfase na relação entre corpo e psique e na denominada pré-história do indivíduo, depreendeu-se o caráter experiencial do desenvolvimento humano. A conquista da capacidade de existir no mundo criativamente mediante um sentido pessoal de real se mantém em questão para o ser humano até a morte como seres que tendem a amadurecer desde sua vida intrauterina. $\mathrm{O}$ caráter experiencial do amadurecimento humano enquanto pessoa total se revela no tempo na temporalidade da existência, vislumbrando-se frutífero diálogo entre Ciência e Filosofia tanto para a promoção da saúde, como para a compreensão da natureza humana desde os primórdios da existência individual.

PALAVRAS-CHAVE: Winnicott; saúde; filosofia; amadurecimento; experiência.
\end{abstract}

\section{ABSTRACT:}

The communication presented at the Philosophy and Health Symposium of the College of Philosophy of PUC Minas, in May 2021, had as subject Dr. Winnicott's ideas and their possible contributions to Philosophy. After a brief presentation by the author, his reflections on human development from the pillars of psychosomatic unit and theory of personal maturity were exposed. The aim was to highlight his notion of health and its respective consequences for the scientific field, notably the medical sciences, through an approach that goes beyond the sphere of the organism and that intends to overcome the mind-body dualism. With an emphasis on the relationship between body and psyche and on the pre-primitive stages of individual development, the experiential character of human development was revealed. The conquest of the capacity to exist in the world creatively through a personal sense of real remains for the human being until death as beings who tend to mature since their intrauterine life. The experiential character of human maturation as a whole person is revealed in time in the temporality of existence, with fruitful dialogue between Science and Philosophy both for promoting health and for understanding human nature since the very beginning of individual existence.

KEYWORDS: Winnicott; health; philosophy; theory of personal maturity; experience.

\footnotetext{
* Graduada em Filosofia pela PUC Minas. E-mail: mrtanadesouza@hotmail.com.
} 
Segundo o Dicionário de tupi antigo, de Eduardo de Almeida Navarro citado por Wikipedia, o termo igarapé provém do tupi, da junção dos termos ygara, que quer dizer canoa, e apé (caminho), donde o significado literal caminho de canoa. O Aurélio indica tratar-se de canal natural, estreito, entre duas ilhas, ou entre uma ilha e a terra firme. Ambientalmente, os igarapés são corredores ecológicos, portanto têm a importante função de possibilitar o deslocamento e o fluxo gênico de animais e plantas e a conservação da biodiversidade (ARAÚJO; BASTOS, 2019). Pelo homem, porque pouco profundos, os igarapés são navegáveis apenas por pequeninas e estreitas embarcações, as canoas. Mesmo assim, os igarapés correm para os rios, e os rios, para outros rios e para o mar.

\section{INTRODUÇÃO}

A presente comunicação toma por base imediata a obra Natureza humana, de 1954, de D. W. Winnicott (1990), para apresentar seu pensamento sobre o ser humano enquanto unidade psicossomática que amadurece, cuja saúde é entendida com sentido próprio positivo, embora complexo e variável segundo o existir pessoal de cada indivíduo em um mundo não desejado.

A obra utilizada, Natureza humana, é resultado do trabalho desenvolvido e aperfeiçoado ao longo de toda a vida de Winnicott e considerada a fonte primeira e principal para o estudo de seu pensamento. Também foram utilizados, de forma complementar, textos de estudiosos do pensamento do autor, notadamente filosóficos.

A teoria do amadurecimento pessoal de Winnicott parece indicar ser frutuoso e necessário o diálogo entre a ciência e a filosofia. Isso porque o autor reconhece a importância das investigações filosóficas para melhor compreensão do homem, favorecendo a promoção de sua saúde de forma integral, abrangendo corpo e psique, organismo e emoções, no que o autor denomina campo psicossomático.

Por outro lado, o autor parece trazer elementos valiosos à Filosofia ao apresentar o amadurecimento como uma conquista individual do ser humano favorecida pelos cuidados do ambiente e que se dá na facticidade, importando em uma capacidade de existir criativamente, com sentido de real na relação consigo mesmo, com os outros e no mundo e que se mantém em questão no presente do amadurecimento até a morte. Logo, tratar do desenvolvimento humano, sua saúde e conhecer meios de promovê-la diz sobre o homem, no mundo. 


\section{O AUTOR, O HOMEM E A FILOSOFIA}

Donald Woods Winnicott (1896-1971), médico pediatra inglês, formou-se psicanalista infantil pela Sociedade Britânica de Psicanálise, contemporâneo de Ana Freud (filha, sucessora intelectual de Sigmund Freud e pioneira da psicanálise infantil) e supervisionado, em sua formação, pela também importante psicanalista infantil, Melanie Klein, tendo sido a psicanálise, especialmente a clássica, freudiana, sua principal interlocutora.

O próprio Winnicott afirma jamais ter deixado de ser médico pediatra, nem de ser psicanalista enquanto médico. Para ele, "a medicina do corpo funde-se naturalmente à medicina psicossomática", e restringi-la ao corpo é como "um país cujas fronteiras são sustentadas artificialmente, a fim de limitar as responsabilidades do médico" (1990, p. 45-46).

As ciências médicas assumem como objetivo a promoção da saúde, seja em si mesma considerada como valor, seja enquanto conhecimento e enfrentamento de doenças. Segundo o autor, "a saúde tem relação com o viver, com a saúde interior e, de modo diverso, com a capacidade de se ter experiência cultural”(WINNICOTT, 1999).

Para Winnicott (1990, p. 172), a natureza humana é tema ilimitado, e a Filosofia possui o mérito de corajosamente buscar entendê-la. O autor abre Natureza humana afirmando que "minha tarefa é o estudo da natureza humana", assim considerando "quase tudo o que possuímos" (1990, p. 21) e quaisquer investigações a seu respeito, inclusive as realizadas pelas ciências médicas em busca da promoção da saúde, devem considerar sua complexidade, tomando o homem em seus múltiplos modos de viver.

Para o autor, “o ser humano é uma amostra-no-tempo da natureza humana” (1990, p. 29). Observa Dias (2003, p. 93) que a perspectiva de Winnicott é de que "todos os fenômenos humanos são um desdobramento temporal da natureza humana, de tal modo que eles não podem ser descritos, em nenhum nível, como algo substancial, sob pena de se desvirtuar a natureza fundamental do homem: a de ser um modo de temporalização".

Assim, para Winnicott, considerando a totalidade da pessoa, a saúde também diz respeito ao seu modo pessoal de existir no mundo e em relação com as coisas e com os demais de acordo com a capacidade pessoal de um viver criativo.

\section{O CORPO, A UNIDADE PSICOSOMÁTICA E A SAÚDE}

Em Natureza humana, o autor trata da saúde, enquanto saúde física e saúde psíquica, buscando evidenciar a inter-relação entre elas, tomando o homem em sua inteireza, corpo e 
psique em unidade psicossomática, ornada pela mente. Também fala das doenças, igualmente como somáticas, psíquicas e psicossomáticas, no intento de superar a abordagem dicotômica e, a seu ver, reducionista corpo-mente que caracterizava o universo científico sobre o homem.

Winnicott reconhece no homem, funcionalmente, corpo e psique necessariamente em inter-relação, pelo que mais apropriado seria falar-se de soma e psique. Soma diz respeito ao "corpo vivo", ao corpo já em elaboração imaginativa pela psique, conduzindo a uma ideia de unidade de homem enquanto pessoa total (DIAS, 2003, p. 104). Corpo e psique são considerados como opostos apenas o necessário para se observar o desenvolvimento e o funcionamento físico e psíquico do homem e suas especificidades, de modo a serem investigados e tratados pelas ciências.

Em Winnicott, o tradicional problema da Filosofia e das Ciências sobre a diferença substancial mente e corpo é substituído por uma diferença operacional entre funções corpóreas e funções psíquicas, e o problema da união, ou não, entre corpo e mente, é sucedido pelo problema da integração daquelas mesmas funções (LOPARIC, 2000).

A concepção de unidade psicossomática leva a que se deixe de considerar o corpo apenas como um organismo biológico, passando a ser um “corpo vivo”, isto é, soma.

A psique, cuja origem etimológica remete à psyché dos gregos antigos como princípio vital presente em todos os seres vivos (DIAS, 2003), confunde-se com a função da elaboração imaginativa. Para o autor, a função de elaboração imaginativa é considerada biologicamente inata no homem, em razão da sua evolução como espécie, e é ela, realizada primeiramente sobre a totalidade do corpo que formará, forjará, fará avançar, em desenvolvimento e complexidade, a psique do indivíduo.

Sublinha-se aqui o entendimento do autor de que corpo e psique devem ser considerados, desde o início, funcionalmente em interação, cuja unidade pode ser alcançada em razão da tendência natural à integração, de origem filogenética.

Pertinente registrar que Winnicott (1990) identifica a mente, cuja atividade é a intelectual do homem, como uma função organizacional realizada pelo cérebro a partir do funcionamento psicossomático, ou seja, psique e corpo em interação. Portanto, a mente e a função intelectual se distinguem da função da elaboração imaginativa e da psique, não havendo que se falar em saúde, e sim maior ou menor capacidade mental ou intelectual.

A saúde física é a saúde do corpo, mas que pode vir a ser comprometida por perturbações emocionais, tratando-se, então, da esfera psicossomática. A promoção da saúde física seria, 
tradicionalmente, o campo da medicina em geral; contudo, a partir de uma abordagem psicossomática, envolveria outros campos do conhecimento.

A saúde psíquica deriva do desenvolvimento da psique do indivíduo, envolve as emoções, próprias do "mundo interno": "o mundo pessoal na medida em que ele é mantido na fantasia, no interior das fronteiras do ego e do corpo limitado pela pele" (WINNICOTT, 1990, p. 104); constitui-se mediante a conquista da capacidade de manter relação pessoal com os próprios impulsos instintivos, próprios do corpo animal humano, e com os relacionamentos externos estabelecidos pelo indivíduo.

A saúde psíquica é uma questão de amadurecimento pessoal. Envolve o "mundo interno", guarda relação com a descoberta pessoal de um sentido de ser em um mundo que não foi pelo indivíduo desejado, mas que é por ele ativamente construído, de modo a poder considerar a si mesmo uma "pessoa total" (whole person). Isso envolve suas relações com outros e no mundo. No entanto, reconhecendo-se a inter-relação corpo-psique, igualmente quanto à psique há que se considerar perturbações de ordem física para o seu desenvolvimento saudável, compondo, aqui também, o campo psicossomático.

Winnicott observa que tanto a saúde física quanto a saúde psíquica importam, reciprocamente, em um sentido de segurança ao indivíduo para seu desenvolvimento integral e, se são promovidas conjuntamente, o fardo da existência será suportado a um menor custo pessoal. Os três "poderes" do ser humano (WINNICOTT, 1990, p. 29), isto é, soma, psique e mente, mediante desenvolvimento psicossomático "coroado" pela atividade mental, constituirão, gradualmente, a autoconsciência pessoal de cada indivíduo, necessariamente em relação com o ambiente (WINNICOTT, 1990, p. 51).

É possível afirmar, por conseguinte, que saúde não guarda correspondência direta opositiva a doenças. O conceito de saúde, aqui, torna-se complexo, e a ausência de doenças é meramente "o ponto de partida para uma vida saudável." (WINNICOTT, 1990, p. 21). O autor, observa-se, trata muitas vezes o tema como "estado de saúde"; do mesmo modo, o ser humano apresenta-se na realidade, segundo o autor, em "estados" diversos.

\section{O AMADURECIMENTO HUMANO E A PRÉ-HISTÓRIA DO INDIVÍDUO}

Para Winnicott, há dois elementos inatos no desenvolvimento humano: a criatividade originária decorrente da elaboração imaginativa e a tendência à integração em uma unidade. Como visto, na base de ambos se reconhece o corpo em desenvolvimento. 
Segundo Winnicott (1990), em algum momento da vida intrauterina após a concepção, o feto/bebê será capaz de algum grau de experiências em razão de já contar com certo desenvolvimento corporal, com a formação e funcionamento do cérebro e ser capaz de motilidade, aqui considerada enquanto capacidade dinâmica de movimento e quietude. Tornase, com isso, também capaz de armazenagem de sensações corporais vividas em imersão naquele ambiente diante de mudanças da temperatura, pressão e ritmo cardiorrespiratório maternos, ruídos, etc. Trata-se de um "primeiro despertar", a passagem de um certo existir vivo ao ser propriamente. Assim, para Winnicott, a partir desse "primeiro despertar", o ser humano já será capaz de armazenar, em algum grau, experiências de seu desenvolvimento, tratando-se da pré-história do indivíduo.

Para o autor:

[...] no momento do nascimento a termo já existe um ser humano no útero, capaz de ter experiências e acumular memórias corporais e até mesmo organizar defesas contra possíveis traumas (como a interrupção da continuidade do ser pela reação contra intrusões do ambiente, na medida em que este falha em sua missão de se adaptar).

De acordo com esse ponto de vista, os fetos que completam o período de gravidez chegam ao momento do parto cada qual com sua capacidade individual (ou sua incapacidade) de lidar com as grandes mudanças que ocorrem naquele momento. (WINNICOTT, 1990, p. 165).

Winnicott coloca-se sob uma possível perspectiva do bebê, entendendo não ser possível falar-se ainda na existência de uma consciência enquanto capacidade de representação, mas de uma "mera consciência" (awareness). A consciência, enquanto capacidade de representação e reconhecimento de uma realidade objetiva, surge apenas após a conquista da integração, o que supõe o assentamento da psique no corpo (pela elaboração imaginativa), a integração como uma unidade pessoal (self) e o estabelecimento da relação com a realidade externa, o que se dá no primeiro ano de vida posterior ao nascimento, quando um longo caminho de amadurecimento do ser humano já foi percorrido.

O reconhecimento do corpo e das sensações corpóreas na base da origem da elaboração imaginativa e desenvolvimento da psique mostram um sentido gestual ou comportamental conferido por Winnicott ao modo de operar da psique e que é anterior, portanto, a representações, verbalizações e simbolizações em geral (LOPARIC, 2000, p. 369-373).

Ainda na vida intrauterina, a elaboração imaginativa consistiria em uma dação de sentido aos movimentos do corpo, portanto pré-representacional, consistente em um princípio de ser, um princípio de desenvolvimento de um si-mesmo espontâneo e, por essa razão, 
originariamente pessoal. Para o autor, falhas no amadurecimento nessas fases iniciais dizem respeito aos acessos à realidade ainda subjetivos, pré-representacionais e, nesses casos, não se trataria de dinâmica ou economia de conflito instintual, mas de amadurecimento e conquista gradual de um sentido de existência real, decorrente da espontaneidade, a partir do corpo em interação com a psique, mediante suficiência ambiental e cuidado provido.

A espontaneidade dos movimentos do bebê, como decorrentes do funcionamento do próprio corpo, mesmo dentro do útero materno, é elemento fundamental de um amadurecimento saudável, para Winnicott.

A experiência pode dar-se conforme as necessidades e a partir delas (caráter de espontaneidade), em um ambiente bom que as satisfaça segundo o ritmo do próprio bebê, o que constitui progressivamente um ambiente confiável e previsível ("ambiente suficientemente bom"), ou pode se dar independentemente de suas necessidades, ocasião em que serão experienciadas como intrusões, interrupções da continuidade de ser, possivelmente traumáticas (angústias impensáveis) (SANTOS, 2006, p. 126). O binômio espontaneidade-angústias impensáveis mostra-se, portanto, como fenômeno humano pré-representacional e pré-verbal do amadurecimento humano.

Winnicott fala de uma passagem da teoria do instinto a uma teoria do ego, diferenciando seu pensamento da psicanálise tradicional. A pessoalidade e o caráter experiencial do desenvolvimento do indivíduo são identificados como amadurecimento do ego, em relação ao qual a pré-história do indivíduo tem papel relevante, assim como a experiência do nascimento e os primeiros estados do desenvolvimento humano, sempre em chave de experiência pessoal em relação com o corpo e o ambiente.

A unidade psicossomática não é dada, não constitui o homem enquanto substância, mas é apenas resultado de uma tendência natural à integração em uma unidade, cuja realização se dá, como possibilidade, no devir do desenvolvimento humano mediante a função da elaboração imaginativa em interação com o corpo, no ambiente. Ademais, ainda que alcançada a integração em uma unidade, ela se mantém precária ao longo da vida. O caráter de conquista, precariedade, falibilidade e pessoalidade da integração, mediante elaboração imaginativa, revela a natureza experiencial do amadurecimento humano como movimento constituidor de sentido em uma teoria do ego, isto é, de desenvolvimento emocional.

Winnicott (1990) se afasta da psicanálise tradicional que, segundo ele, tem como objeto o sujeito já estruturado e que, portanto, representa e se relaciona com uma realidade exterior objetiva, deixando de considerar o amadurecimento anterior à integração. Dias (2003) aponta 
que a psicanálise tradicional, inclusive Melanie Klein, não teria conseguido afastar-se da explicação mecanicista do homem, pelo elemento da pulsão, responsável pela articulação entre corpo e mente, que colocaria em marcha o psiquismo, segundo um modelo físico-espacial regido por leis válidas do aparelho psíquico e teorizadas pela metapsicanálise quanto a sua dinâmica ou economia.

Winnicott nos lembra, pela noção de "mundo interior" que se constitui paulatinamente, que o ser humano não se limita a ser um corpo, um organismo biológico, ainda que dotado de um psiquismo com funcionamento consciente e também inconsciente. $\mathrm{O}$ ser humano amadurece emocionalmente, possuindo um passado, um presente e um futuro sempre em questão no presente do indivíduo e até a morte. Amadurecer consiste justamente em uma capacidade conquistada, mediante cuidado ambiental, e que se dá não necessariamente, mas precariamente, sempre com chance de fracasso, devendo ser mantida durante toda a vida. Por isso, o amadurecimento estará, para o homem, sempre em questão e influencia o que se pode chamar de estado de saúde.

\section{AMADURECER COMO EXPERIÊNCIA DE EXISTIR}

Falar de estado de saúde, segundo o pensamento de Winnicott, envolve a experiência de cada indivíduo em sua história de amadurecimento desde o "primeiro despertar", quando alcançou ser ainda em sua pré-história, cuja continuidade, embora seja uma tendência natural, não está assegurada, é precária e variável conforme os cuidados ambientais.

Em que pese Winnicott não tratar conceitualmente de experiência (DIAS, 2003), este conceito se depreende de seu pensamento. Diz respeito à espontaneidade e às angústias impensáveis e envolve a conquista de ser, de continuar sendo, mediante um sentido real de ser no mundo, mediante um sentimento próprio, pessoal e criativo de real. O real, no pensamento de Winnicott, não é a realidade externa, mas a possibilidade de se estabelecer uma relação criativa e espontânea do indivíduo, que amadurece, com a realidade do mundo. É também uma conquista da maturidade do ego, uma capacidade adquirida nos processos de integração, personalização e realização.

A experiência não se identifica com a maturescência biológica do organismo humano, nem é resultado de um processo estímulo-resposta sobre ele; tampouco é produto da atividade intelectual de assimilação, acomodação e resposta na forma de ação de um sujeito nas formas de conhecimento ou desempenho. A experiência diz respeito a um sentido pessoal de ser e de 
poder, ou não, continuar a ser em um tempo presente do amadurecimento e, em razão do que se entende por amadurecimento, na temporalidade.

Segundo Winnicott (1999), para que se possa falar de um estado de saúde, antes da conquista da capacidade do indivíduo de estabelecer relações de uso com o mundo e que importa em uma capacidade de fazer, primeiramente, como condição, ele deverá conquistar a capacidade de ser e de continuar a ser ao longo de toda sua existência, o que importará em existir, mais além do que meramente viver. O meramente viver é próprio de todos os seres vivos. Portanto, o estado de saúde diz respeito, primeiramente, à conquista de ser, de continuar a ser como experiência de existir.

O amadurecimento individual se dá de forma complexa e não linear, em movimentos de avanços e recuos constantes, estando todas as tarefas e conquistas implicadas entre si, tanto na interação psico-soma, como enquanto passado, presente e futuro sempre em questão no presente do amadurecimento, em clara demonstração da complexidade da existência humana e de sua temporalidade.

\section{CONCLUSÃO}

O pensamento de Winnicott nos motiva a uma aproximação entre ciência e filosofia, a primeira enquanto pretenso lugar da terra firme e do conhecimento seguro, cujos limites se supõe confinarem com o mar agitado e incerto da segunda. Isso porque falar de estado de saúde e de sua promoção, segundo seu pensamento, não se limita à saúde do corpo; exige que se leve em conta a experiência individual de ser enquanto amadurecimento. Este, por sua vez, tem início sobre a base do corpo elaborada imaginativamente desde o "primeiro despertar", quando se alcançou ser, cuja integração em uma unidade, embora seja uma tendência natural, não está assegurada, é precária e encontra-se em jogo até a morte, como continuidade de ser pessoal e real, na temporalidade da existência.

O estado de saúde, como objeto de preocupação das ciências médicas, importa também, segundo o pensamento de Winnicott, na conquista e manutenção de um sentido pessoal real e criativo de ser no mundo. Portanto, assim, o pensamento de Winnicott parece não prescindir da manutenção de um corredor ecológico entre a ciência e a filosofia, no que se refere ao homem e à sua saúde.

Retornando aos igarapés, Guimarães Rosa (2013), em seu A terceira margem, nos deixa perplexos diante do pai, que abandona a terra firme e passa a viver, ano após ano, em sua 
pequena canoa, no meio do rio; tanto quanto, diante do filho, que foge da tarefa de substituí-lo, apesar de reconhecer o peso dos anos sobre os ombros daquele que o antecedeu, seu pai. A família não entende o que se passa com o pai e cogita ser loucura, contudo se recusa a tratar por louca a pessoa em seu silêncio.

Ocorre que entre a terra firme, de onde saiu o pai, do conto de Guimarães Rosa, e o leito do rio, onde passou a viver em sua canoa, correm os igarapés. Winnicott, ao que parece, nos inspira a pensar que talvez os igarapés fossem um lugar onde devêssemos também buscar, na ciência e na filosofia, respostas.

\section{REFERÊNCIAS}

ARAÚJO, Thatiane Maria Souza de; BASTOS, Frederico de Holanda. Corredores Ecológicos e conservação da biodiversidade: aportes teóricos e conceituais. Revista da Casa da Geografia de Sobral (RCGS), Sobral, v. 21, n. 2, p. 716-729, 30 set. 2019. Disponível em: https://rcgs.uvanet.br/index.php/RCGS/article/view/575/431. Acesso em: 25 abr. 2021.

DIAS, Elsa Oliveira. A teoria do amadurecimento de D. W. Winnicott. RJ: Imago, 2003. Disponível em:

https://www.academia.edu/31744562/A_Teoria_do_Amadurecimento_de_D_Winnicott_Elsa_ Oliveira_Dias_1_pdf. Acesso em: 25 abr. 2021.

IGARAPÉ. In: FERREIRA, Aurélio Buarque de Holanda. Novo dicionário Aurélio da língua portuguesa. 2. ed. Rio de Janeiro: Nova Fronteira, 1986.

LOPARIC, Zeljko. O “animal humano". Natureza humana (on-line), São Paulo, v. 2, n. 2, p. 351-397, dez. 2000. Disponível em:

http://pepsic.bvsalud.org/scielo.php?script=sci_arttext\&pid=S1517-

24302000000200005\&lng=pt\&nrm=iso. Acesso em: 25 out. 2020.

NAVARRO, Eduardo de Almeida. Igarapé. In: WIKIPEDIA: a enciclopédia livre. [São Francisco, CA: Wikimedia Foundation, 2017]. Disponível em:

https://pt.wikipedia.org/wiki/Igarap\%C3\%A9\#cite_note-2. Acesso em: 25 abr. 2021.

ROSA, Guimarães. A terceira margem do rio. 22 mar. 2013. Disponível em:

https://contobrasileiro.com.br/a-terceira-margem-do-rio-conto-de-guimaraes-rosa/. Acesso em: 25 abr. 2021.

SANTOS, Eder Soares. D. W. Winnicott e Heidegger: a teoria do amadurecimento pessoal e a acontecência humana. 2006. 243p. Tese (Doutorado) - Universidade Estadual de Campinas, Instituto de Filosofia e Ciências Humanas, Campinas, SP. Disponível em:

http://www.repositorio.unicamp.br/handle/REPOSIP/281077. Acesso em: 25 abr. 2021.

WINNICOTT, D. W. O conceito de indivíduo saudável. In: WINNICOTT, D. W. Tudo começa em casa. 3. ed. São Paulo: Martins Fontes, 1999. p. 3-22. Disponível em: 
https://www.academia.edu/41886627/TUDO_COMECA_EM_CASA_WINNICOTT_. Acesso em: 25 abr. 2021.

WINNICOTT, Donald Woods. Natureza humana. Rio de Janeiro: Imago, 1990. 